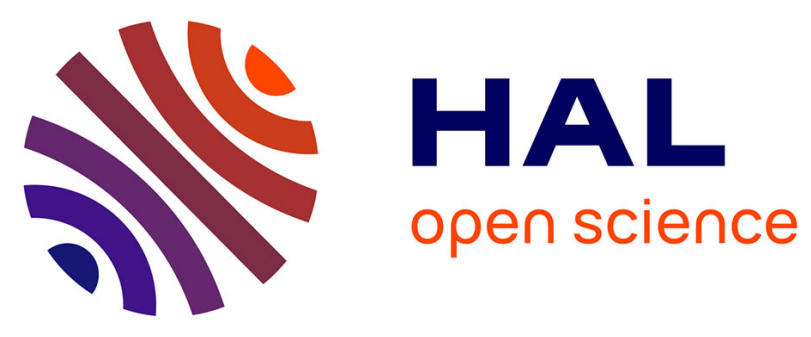

\title{
Negotiation Strategy for Economical Reuse in Closed-Loop Supply Chains
}

Yoshitaka Tanimizu, Kenta Matsui, Yuusuke Shimizu, Koji Iwamura, Nobuhiro Sugimura

\section{- To cite this version:}

Yoshitaka Tanimizu, Kenta Matsui, Yuusuke Shimizu, Koji Iwamura, Nobuhiro Sugimura. Negotiation Strategy for Economical Reuse in Closed-Loop Supply Chains. IFIP International Conference on Advances in Production Management Systems (APMS), Sep 2014, Ajaccio, France. pp.382-389, 10.1007/978-3-662-44736-9_47 . hal-01387902

\section{HAL Id: hal-01387902 \\ https://inria.hal.science/hal-01387902}

Submitted on 26 Oct 2016

HAL is a multi-disciplinary open access archive for the deposit and dissemination of scientific research documents, whether they are published or not. The documents may come from teaching and research institutions in France or abroad, or from public or private research centers.
L'archive ouverte pluridisciplinaire HAL, est destinée au dépôt et à la diffusion de documents scientifiques de niveau recherche, publiés ou non, émanant des établissements d'enseignement et de recherche français ou étrangers, des laboratoires publics ou privés.

\section{(c)(1)}

Distributed under a Creative Commons Attribution| 4.0 International License 


\title{
Negotiation Strategy for Economical Reuse in Closed- Loop Supply Chains
}

\author{
Yoshitaka Tanimizu, Kenta Matsui, Yuusuke Shimizu, Koji Iwamura, and Nobuhiro \\ Sugimura \\ Graduate School of Engineering, Osaka Prefecture University, Osaka, Japan \\ tanimizu@osakafu-u.ac.jp
}

\begin{abstract}
Environmental problems are recognized as one of the most serious issues in these last few decades. Green supply chain management and sustainable supply chain management have gained increasing attention within both academia and industry. Previous studies proposed a closed-loop supply chain model and a negotiation protocol for increasing the amount of reused products and reducing waste products. This study improves the negotiation protocol for further increasing the reused products and reducing the waste. A remanufacturer can economically collect a lot of used products by negotiating with a client in consideration of both the required prices from the remanufacture and the possible times to dispose of the used products from the client. A prototype of a simulation system for a closed-loop supply chain is developed in order to evaluate the effectiveness of the new negotiation protocol. Experimental results show that the new protocol can reuse more products than the previous one.
\end{abstract}

Keywords: Closed-loop supply chain, Reverse supply chain, Reuse, Negotiation, Scheduling, Genetic algorithm, Weibull distribution.

\section{Introduction}

Environmental problems are recognized as one of the most serious issues in these last few decades. Many manufacturing enterprises focus on incorporating not only economical but also environmental concerns into their strategic decisions [1]. Green supply chain management [2,3] and sustainable supply chain management [4-7] have gained increasing attention within both academia and industry. The concept of the green supply chain management (GrSCM) covers all the phases of a product's life cycle, from the extraction of raw materials through the design, production and distribution phases, to the use of products by consumers and their disposal at the end of the product's life cycle including reconditioning, reuse, and recycling of products.

Products and materials are returned from customers to suppliers or manufacturers through reverse supply chains in order to be recycled, reused or reconditioned. Gungor and Gupta [8] indicated that the effort must be made for environmentally conscious manufacturing and product recovery systems to be profitable so that the incentive for development and planning of these systems continues. Then, it is required to establish a method for reconditioning, reuse, and recycling of used products

adfa, p. 1, 2011.

(C) Springer-Verlag Berlin Heidelberg 2011 
in consideration of the feasibility of realizing a balance between environmental and economic concerns.

Previous study have proposed a basic model of closed-loop supply chains and a negotiation protocol for reusing products in consideration of economic efficiency [9]. The negotiation protocol provides a method for synchronizing the demand of reusable parts and the supply of used products among the organizations in the closed-loop supply chains. However some used products may become waste products by inconsistency between the demand and the supply of the used products from the viewpoint of product value. This study improves the negotiation protocol for further increasing the reused products and reducing the waste. A customer usually discards a product by stochastic means in consideration of its life cycle. New protocol provides a customer with a method for discarding a product systematically. A remanufacturer can prospectively enter into a contract with a customer through negotiation with the customer in consideration of both the required prices from the remanufacturer and the possible time to dispose of the used product from the customer.

The reminder of this paper is organized as follows. Section 2 shows literature review. Section 3 briefly describes the previous supply chain model. Section 4 explains new negotiation protocol. Finally, Section 5 demonstrates experimental results.

\section{$2 \quad$ Literature Review}

A large number of literatures have been published on a closed-loop supply chain which involves studies on network design problems, product acquisition management, marketing-related issues, etc. [10]. Guide et al. [11] takes a contingency approach to explore the factors that impact production planning and control for closed-loop supply chains that incorporate product recovery. Nielsen and Bruno [12] analyzed the possibility to utilize closed loop supply chains in mass customization settings and required certain aspects to be considered regarding product design as well as manufacturing and supply chain design. Hassini et al. [6] indicated that quite few papers addressed the pricing issue in a sustainable supply chain context during the last decade.

The market requires environmentally conscious products, such as electric vehicles and wind turbines. However, most of them include rare earths and other rare materials in main component parts, such as batteries and magnets. The U.S. Department of Energy reports that five rare earth elements, such as dysprosium, terbium, europium, neodymium and yttrium, are found to be critical in the short term (present - 2015) and other elements, such as cerium, indium, lanthanum and tellurium, are found to be near-critical [13]. The approach to proactively address material supply risks and prevent supply chain disruptions while building a robust clean energy economy has three pillars: achieving globally diverse supplies, identifying appropriate substitutes, and improving capacity for recycling, reuse and more efficient use of critical materials. Used products that incorporate rare resources like rare earths can be considered as a valuable resource.

A product is usually discarded in consideration of its life cycle. Takata et al. [14] analyzed the actual life cycle data of copying machine. Based on the analysis of the 
data, they proposed several models for identifying a collection rate and a discard rate of copying machines. Umeda et al. [15] analyzed product lifecycles of several products, such as a single use camera, a photocopier, and an automatic teller machine (ATM), from the viewpoint of the reusability. They point out that a product can be reused only when a manufacturer manufactures and sells same types of products in the market. In consideration of the reusability of product in the market, the used product should be returned from customers to suppliers or manufacturers as soon as possible, since the product life cycle appears to becoming shorter in recent years.

A lot of used products may become waste products in traditional recovery approaches, since customers discard products without consideration for reuse of the products whenever they want. A strategy for economical reuse of products is required to collect suitable products from customers and to provide manufacturers with reusable parts disassembled from the used products. Our study proposes a negotiation protocol which synchronizes the demand of reusable parts and the supply of used products among the organizations in the closed-loop supply chains. In the case where a lot of usable parts are required for generating new products, customers are stimulated to discard products for reuse. On the other hand, when few parts are required, customers are discouraged from discarding products. As if the remanufacturer deals with customers like virtual warehouses, the remanufacturer can economically collect suitable used products without various kinds of additional cost for warehouse and safety stock.

\section{Previous Supply Chain Model}

\subsection{Modeling of Forward Supply Chains}

This section briefly describes a model of forward and reverse supply chains which we have proposed in previous studies [8,16,17], in order to help understanding our closed-loop supply chain strategy. The previous studies have represented a framework for dynamically forming and reconfiguring a supply chain as a dynamic supply chain $[16,17]$. Each organization in the supply chains can change business partners for every order to find suitable business partners and enter into profitable contracts.

A three-layered supply chain model consisting of a client, a manufacturer, and a supplier has been proposed as a basic model of forward supply chain which involves make-to-order (MTO) companies with no inventories [17]. It is assumed that only the supplier has sufficient raw materials but no inventory of final products. The model has provided with both the negotiation process to determine the suitable prices and delivery times of products among the three-layered organizations and the modification process of the production schedules in the supplier and the manufacturer. A client and a manufacturer sequentially send orders which include the requirements of delivery times and prices of the ordered products. A supplier and a manufacturer modify their existing production schedules by using a genetic algorithm (GA) and send offers for the orders, respectively. The offers include information about possible delivery times and bid prices of the ordered products. The actual delivery times and prices are determined by the negotiation processes among the organizations. 


\subsection{Modeling of Closed-Loop Supply Chains}

The forward supply chain model extended to a closed-loop supply chain model consisting of both MTO companies in forward supply chains and remanufacturing-toorder companies in reverse supply chains [8]. Figure 1 shows a basic model of a closed-loop supply chain. A model component in the reverse supply chain receives a used product from a client and provides assembly manufacturers with usable parts. The component is referred to as a remanufacturer in the study.

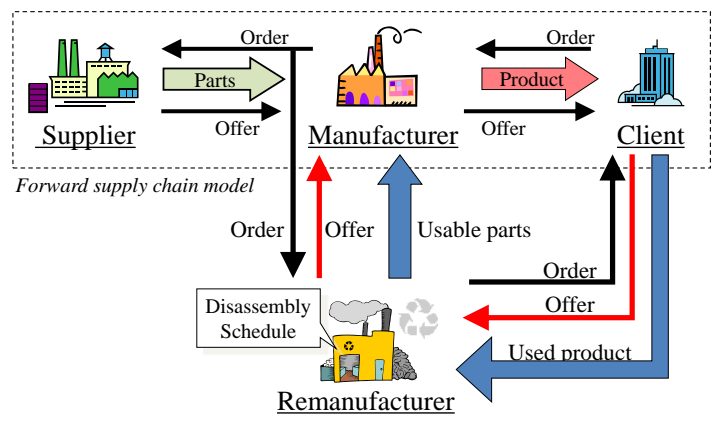

Fig. 1. Closed-loop supply chain model

A remanufacturer has neither stock of usable parts nor used products. A remanufacturer generates an order for used product and sends it to clients when the remanufacturer receives an order for a usable part from a manufacturer. After receiving an offer for a used product from a client, a remanufacturer generates an offer for a usable part and sends it to a manufacturer. A remanufacturer modifies its disassembly schedule and estimates the possible delivery time $d t r_{s, h, n}^{F}$ and the bid price $p c r_{s, h, n}^{F}$ of the usable part by using the following equations.

$$
\begin{gathered}
d t r_{s, h, n}^{F}=c t r_{s, h, n} \\
p c r_{s, h, n}^{F}=t c r_{s, h, n}+r w r_{s, h, n}-p n r_{s, h, n}+\sum_{g=1}^{G} \Delta p n r_{s, h, g}^{R v(s, n, r)}
\end{gathered}
$$

where

$c t r_{s, h, n} \quad$ Completion time of a usable part recovered by remanufacturer $R_{s}$

$t c r_{s, h, n} \quad$ Total cost for buying, disassembling and repairing of a used product

$r w r_{s, h, n} \quad$ Reward for a usable part required by remanufacturer $R_{s}$

$p n r_{s, h, n} \quad$ Penalty charge due to delay in delivery time of a usable part

The estimated profit $e p f_{s, h, n}$ is calculated by the following equation.

$$
e p f_{s, h, n}=r w r_{s, h, n}-p n r_{s, h, n}+\sum_{g=1}^{G} \Delta p n r_{s, h, g}^{R v(s, n, r)}
$$


A remanufacturer considers a balance between supply and demand of reusable parts in the negotiation protocol. When a lot of usable parts are required by manufacturers, a remanufacturer stimulates clients to discard products for reuse by indicating high required prices for the used products to the clients. The clients discard products even if the products don't satisfy the condition of their life cycles estimated based on the Weibull distribution which is commonly used to model life data [18]. On the other hand, when few usable parts are required, remanufacturers indicate low required prices to discourage clients from discarding products. Then, the remanufacturer can increase the amount of reused products whenever they want and reduce waste products.

\section{$4 \quad$ Negotiation Protocol}

This study improves the negotiation protocol to increase the reusability of products. There are three ways for a remanufacturer to obtain used products in the following:

1. Push type discarding strategy: This is a conventional approach. A client discards a product by stochastic means in consideration of its life cycle. Failure rate of product is usually used to estimate when a client discards a product. The Weibull distribution is used in the study to estimate product's life cycle. A client discards a product, when it has been used beyond its life cycle. The discarded products should be stored temporarily, since a client does not consider the condition of reuse of the product. A remanufacture can obtain only the stored product for reuse. In the case where no remanufacturers need the stored product for a certain period, it must be disposed as a waste product.

2. Pull type discarding strategy: This is proposed in the previous research. A remanufacturer stimulates the intention of a client to discard a product, when a used product is required for reuse. A remanufacturer indicates high required prices for a used product to a client. The product's value is estimated based on the Weibull distribution in the study. It decreases with the time of usage of the product. The client evaluates a motivation for discarding a product by using the following equations and determines which product is discarded. If a much lower price is indicated for a used product, it is stochastically discarded and may become a waste product.

$$
\begin{gathered}
m v_{p^{\prime}, n^{\prime}} \geq r n \\
m v_{p^{\prime}, n^{\prime}}=\frac{p c r_{s, n}^{O}-\left(P V(t)-d c c_{p^{\prime}, n^{\prime}}\right)}{p c r_{s, n}^{O}} \\
P V(t)=P V(0) \times \exp \left\{-\left(\frac{t}{\eta}\right)^{\beta}\right\}
\end{gathered}
$$

where

$m v_{p^{\prime}, n^{\prime}} \quad$ Motivation for providing a remanufacturers with a product for reuse 


$\begin{array}{ll}r n & \text { Random numbers } \\ p c r_{s, n}^{o} & \text { Required price for a product. It is determined by a remanufacturer } \\ P V(t) & \text { Product's value. It is estimated based on the Weibull distribution. } \\ d c c_{p^{\prime}, n}, & \text { Cost for discarding a product by client } C_{p}, \\ P V(0) & \text { Initial value of product. It equals to the purchase price of product. } \\ \beta & \text { Shape parameter which determines the mode of failure. } \\ \eta & \text { Scale parameter which defines the life of product. } \\ t & \text { Time of usage of product. }\end{array}$

3. Negotiation type discarding strategy: In the case where a client does not accept an order from a remanufacturer for discarding a product from the viewpoint of the required price, the client provides the remanufacturer with a possible time to dispose of the product as an offer. The product's value decreases with the time of usage of product according to the Weibull distribution, as shown in Fig. 2. The client estimates the time when the product's value equals to the required price sent from the remanufacturer by using the following equation.

$$
\ln t=\ln \eta-\frac{1}{\beta} \ln \left\{\ln \left(\frac{P V(t)}{P V(0)}\right)\right\}
$$

The remanufacturer evaluates the offer from the client by modifying a disassembly schedule and estimates a profit by using Eq. (3). The remanufacturer prospectively enters into a contract with the client by accepting the offer from the client. Then, the remanufacturer can obtain a lot of used products by negotiating with the client in consideration of both the required prices from the remanufacturer and the possible time to dispose of the used products from the client.

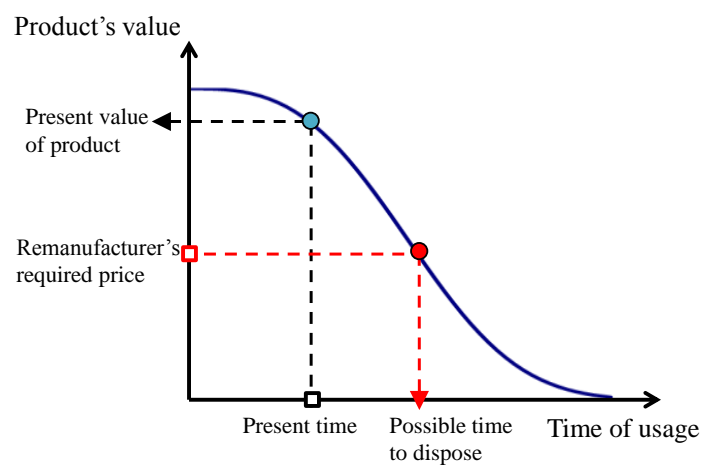

Fig. 2. Estimation of time to dispose of product based on the Weibull distribution

\section{Computational Experiments}

A prototype of a simulation system for closed-loop supply chains has been developed using Windows-based networked computers (Intel Core 2 Duo E8500 3.16 GHz CPU 
with 1.99 GB of RAM). Two suppliers, two manufacturers, a remanufacturer, and a client were implemented as agents on different six computers, respectively.

In the initial conditions, the suppliers and the manufacturers had same job-shop type production schedules consisting of 5 resources and 20 contracted parts, and 10 resources and 20 contracted products, respectively. The client continuously generated 100 new orders and negotiated with two manufacturers during the experiments for about 6 hours. The manufacturers generated orders and negotiated among the two suppliers and one remanufacturer every 30 seconds of bidding time in order to generate offers for the client. Population size, crossover rate, and mutation rate of the GA were $30,0.8$, and 0.2 , respectively.

Experimental results of the model with new negotiation protocol including negotiation type discarding strategy were compared with ones of the model with the previous protocol including only push and pull type discarding strategies. Ten experiments were carried out for the new model and the previous model, respectively. The experimental results are summarized in Table 1 . The remanufacturer in the new model can increase the amount of reused products more than the one in the previous model. The new model can reuse about $10 \%$ more products than the previous one. According to the rate of reused parts in new products, there are more chances to assemble the reusable parts into new products in the new model than the one with the previous model. However the remanufacturer doesn't obtain a very large profit, since it should pay the penalty charge in the case of delay in the required delivery time of usable part.

Table 1. Comparison between experimental results of the two models

\begin{tabular}{lll}
\hline & Previous model & New model \\
\hline Number of reused products [av] & 24.8 & 31.7 \\
\hline Number of waste products [av] & 36.3 & 31.6 \\
\hline Rate of reuse to discard [av] $(\%)$ & 40.6 & 50.0 \\
\hline Rate of reused parts in new products [av] $(\%)$ & 33.1 & 42.1 \\
\hline Profit of remanufacturer [av] $\left(* 10^{3} \$\right)$ & 62.8 & 64.8 \\
\hline
\end{tabular}

\section{Conclusion}

Previous studies proposed a closed-loop supply chain model and a negotiation protocol for increasing the amount of reused products and reducing waste products. This study improves the negotiation protocol for further increasing the reused products and reducing the waste. A remanufacturer can prospectively enter into a contract with a client by accepting the offer for possible time to dispose of product. Then, a lot of used products are economically collected by a remanufacturer through negotiation with a client in consideration of both the required prices from the remanufacture and the possible times to dispose of the used products from the client. Some experiments were carried out by using the developed simulation system for a closed-loop supply chain. Experimental results of the model with new negotiation protocol were compared with the one of previous protocol. The results show that the new protocol can reuse about $10 \%$ more products than the previous one. 


\section{References}

1. BearingPoint: 2008 Supply Chain Monitor "How Mature is the Green Supply Chain?", Survey report (online), available from <http://www.supplychainstandard.com> (2008)

2. Srivastava, S. K.: Green Supply-Chain Management: a State-of-the-Art Literature Review, International Journal of Management Reviews, Vol. 9, Issue 1, pp. 53-80 (2007)

3. Sarkis, J., Zhu, Q., Lai, K.: An Organizational Theoretic Review of Green Supply Chain, International Journal of Production Economics, Vol. 130, pp.1-15 (2011)

4. Seuring, S., Muller M.: From a Literature Review to a Conceptual Framework for Sustainable Supply Chain Management, Journal of Cleaner Production, Vol. 16, pp. 1699-1710 (2008)

5. Gupta, S., Palsule-Desai, O. D.: Sustainable Supply Chain Management: Review and Research Opportunities, IIMB Management Review, Vol. 23, pp. 234-245 (2011)

6. Hassini, E., Surti., C., Searcy, C.: A Literature Review and a Case Study of Sustainable Supply Chains with a Focus on Metrics, International Journal of Production Economics, Vol. 140, pp. 69-82 (2012)

7. Seuring, S.: A Review of Modeling Approaches for Sustainable Supply Chain Management, Decision Support Systems, Vol. 54, pp. 1513-1520 (2013)

8. Gungor, A., Gupta, S. M.: Issues in Environmentally Conscious Manufacturing and Product Recovery: a Survey, Computers and Industrial Engineering, Vol.36, pp.811-853 (1999)

9. Tanimizu, Y., Shimizu, Y., Iwamura, K., Sugimura, N.: Modeling and Simulation of Closed-Loop Supply Chains Considering Economic Efficiency, Advances in Production Management System, Part I, pp. 461-468 (2013)

10. Llgin, M. A., Gupta, S. M.: Environmentally Conscious Manufacturing and Product Recovery (ECMPRO): A Review of the State of the Art, Journal of Environmental Management, vol. 91, pp. 563-591 (2010)

11. Guide, V. D. R., Jayaraman, V., Linton, J. D.: Building Contingency Planning for ClosedLoop Supply Chains with Product Recovery, Journal of Operations Management, Vol. 21, pp. 259-279 (2003)

12. Nielsen, K., Bruno, T. D.: Closed Loop Supply Chains for Sustainable Mass Customization, Advances in Production Management System, Part I, pp. 425-432 (2013)

13. The U.S. Department of Energy: Critical Materials Strategy (2011)

14. Takata, S., Watanabe, M., Ohbayashi, Y.: Collection Rate Estimation Model in ClosedLoop Manufacturing, Proc. of CIRP International Conference on Life Cycle Engineering, pp. 601-606 (2006)

15. Umeda, Y., Kondoh, S., Sugino, T., Yoshikawa, H.: Analysis of Reusability using 'Marginal Reuse Rate', CIRP Annals -Manufacturing Technology, Vol. 55, Issue 1, pp. 41-44 (2006)

16. Tanimizu, Y., Yamanaka, M., Iwamura, K., Sugimura, N.: Multi-Agent Based Dynamic Supply Chain Configuration Considering Production Schedules, Proc. of International Symposium on Flexible Automation, pp. 572-578 (2006)

17. Tanimizu, Y., Ozawa, C., Shimizu, Y., Orita, B., Iwamura, K., Sugimura, N.: Flexible Multi-Layered Dynamic Supply Chain Models with Cooperative Negotiation, International Journal of Automation Technology, Vol. 7, No. 1, pp. 128-135 (2013)

18. Mazhar, M. I., Kara, S., Kaebernick, H.: Remaining Life Estimation of Used Components in Consumer Products: Life Cycle Data Analysis by Weibull and Artificial Neural Networks, Journal of Operations Management, Vol. 25, pp. 1184-1193 (2007) 